\title{
Relationship among Workplace Spirituality, Meaning in Life, and Psychological Well-being of Teachers
}

\author{
Jin-long Liang ${ }^{1}$, Lan-xiang Peng ${ }^{2}$, Si-jie $\mathrm{Zhao}^{2}$, Ho-tang $\mathrm{Wu}^{3, *}$ \\ ${ }^{1}$ Department of Education, School of Education Sciences, Xinjiang Normal University, China \\ ${ }^{2}$ College of Education, Shandong Normal University, China \\ ${ }^{3}$ Department of Education, National Kaohsiung Normal University, Taiwan
}

Copyright $\mathrm{C} 2017$ by authors, all rights reserved. Authors agree that this article remains permanently open access under the terms of the Creative Commons Attribution License 4.0 International License

\begin{abstract}
This study set out to analyze the relationship among teachers' workplace spirituality, sense of meaning in life, and psychological well-being. Taking 610 teachers as its subjects, the study employed three scales: one to measure the subjects' sense of workplace spirituality, another to measure their sense of meaning in life, and a third to measure their sense of psychological well-being. These three scales were pretested and found to have good reliability and validity. The questionnaire data were analyzed using hierarchical regression in order to understand the explanatory power of the predictors(workplace spirituality and meaning in life) to dependent variable of psychological well-being. The results showed $62.70 \%$ explanatory power. According to the research findings, this study suggests that teachers should understand the importance of having workplace spirituality, of being psychologically sound and of feeling they have a meaningful life. Future studies may further explore the factors that influence teachers' sense of psychological well-being.
\end{abstract}

Keywords Workplace Spirituality, Meaning in Life, Psychological Well-being

\section{Introduction}

Having a sense of a workplace spirituality, psychological well-being and a meaningful life are extremely important factors for an individual's mental and physical development and workplace performance. For example, a communal workplace spirituality can be defined as the recognition that employees have an inner life that nourishes and is nourished by the meaningful work that takes place in the context of a community (Ashmos \& Duchon, 2000)[1]. This can increase the employees' sense of commitment in the workplace (Krishnakumar \& Neck, 2002; Milliman, Ferguson, Trickett, \& Condemi, 1999) [2, 3], the performance and development of ethical organizations (Garcia-Zamor, 2003) [4], organizational commitment, intrinsic job satisfaction, the intention or lack thereof to quit, job involvement, and organization-based self-esteem (Milliman, Czaplewski, \& Ferguson, 2003) [5]. On the other hand, one's sense of meaning in life has to do with the degree of significance one feels his or her life, or being, or existence has (Steger, Frazier, Oishi, \& Kaler, 2006) [6]. Having a clear sense of one's life's meaning and purpose is of course regarded as a positive trait and a psychological strength (Seligman \& Csikszentinihalyi, 2000) [7], an indicator of well-being (Ryff, 1989) [8] that can promote one's continual growth and/or, in certain cases, one's recovery (Lent, 2004). [9]

Psychological well-being is closely tied to an individual's awareness that he or she has, or will have, a meaningful and self-fulfilling life (Keyes, Shmotkin, \& Ryff, 2002) [10]. Some studies have found that psychological well-being can enhance resilience, endurance, and optimism (Salsman et al., 2014) [11]. In addition, maintaining a strong sense of psychological well-being in our later life may help us to maintain our physical health and strength (Gale, Cooper, Deary, \& Aihie Sayer, 2014) [12]. In fact, having a clear sense of the meaning of one's job - aided by a communal spirit in the workplace - as well as a sense of psychological well-being and of meaning in life clearly all play a crucial part in every individual's development. These three factors are clearly interrelated or correlated.

In the first place, having a sense of communal sprit in the workplace is closely tied to our sense of psychological well-being. It is what allows people to find meaning and self-fulfillment through their job, their work (Kinjerski, 2013) [13]. Moreover, a sense of having a meaningful job makes it much easier for employees to learn the necessary skills and to develop a greater sense of responsibility, for it means they think their job, their work is important (Wrzesniewski, 2001) [14]. Thus, as De Klerk (2005) [15] points out, the feeling that their work is meaningful will motivate employees to work harder and to aim at a higher level of performance, which will lead to a still greater sense of job satisfaction and thus too of self-satisfaction, of psychological well-being. 
Arnold, Turner, Barling, Kelloway, and McKee's (2007) [16] empirical research clearly suggests that a sense of having a communal workplace spirituality is closely correlated with that of psychological well-being.

The sense of meaning in life is of course also closely correlated with that of psychological well- being (De Klerk, 2005) [15]. Some empirical research results do clearly show this correlation. For instance, it is found in Shek's (1992) [17] study of 2,150 Hong-Kong high school students; Ho, Cheung, and Cheung (2010) [18] did a study of 1,807 Hong-Kong teenagers and got same results. In other studies, Vehling et al (2011) [19] used 270 cancer patients as their research subjects, and the results showed, once again, that meaning-related life attitudes can enhance psychological well-being. Asflakseir (2012) [20] used 60 Muslim students in England as his research subjects, and again found that our sense of meaning in life has positive correlation with our sense of psychological well-being. Although the research subjects above were all teenagers, undergraduates, and cancer patients, the results all show that psychological well-being and a positive sense of life's meaning are closely correlated.

To sum up, it has been clearly shown that the senses of psychological well-being, of having a communal workplace spirituality and of meaning in life are very closely related. However, in past studies of these same three variables almost all researchers used the method of Pearson product-moment correlation to analyze these "psychological" relationships or correlations, but no research studies have so far used the method of hierarchical regression to analyze them. Therefore the present study did adopt hierarchical regression as its analytical method. However, since this method puts different "blocks" into the equation in an order based on previous research results (Chiu, 2006) [21], the sequence must be decided first. In our study, then, there are three demographic variables (gender, marital status, and service years), and the central research question has to do with the sense of one's workplace spirituality, in terms of a sense of one's work being meaningful, a sense of community, and a sense of identification with one's job, company, organization -in relation to the issue of one's meaning in life - which again has three aspects - freedom of will, will to meaning, and the meaning of life.

Here the sequence of these "aspects" was put into the equation as follows. The first variables were demographic-gender, marital status, and years of service-which were ascertained from the experimental subjects at the very beginning, and were not influenced by other explanatory variables. Therefore, in the hierarchal regression, they were treated as the control variables in order to control the impact of the external factors (Chiu, 2006) [21]; thus they were set within the first block. Then, a sense of workplace spirituality will influence one's perception or sense of the meaning in life, as the former will serve to enhance the individual's sense that his/her inner life is meaningful since his work (job) is meaningful. That is, one's work (job) may cause him/her to attain a more complete, harmonious or elevated mind or mental dimension, thereby further enriching his/her inner as well as outer self and thus attaining a clearer awareness of having a meaningful life. (Ashmos \& Duchon, 2000) [1]. This process is what Meraviglia (1999) [22] has described: the sense of meaning in life is an outcome or effect of one's pre-existing spirituality. Thus the three aspects of "workplace spirituality" were arranged in the second block, and the awareness of the "meaning in life" in the last block.

\section{Research Design}

This research study used a questionnaire and purposive sampling to investigate and analyze the relationships between and among the workplace spirituality, meaning in life, and degree of psychological well-being of teachers in Taiwan.

\subsection{Research Subjects}

We adopted a purposive sampling method to establish our group of subjects, all of whom are teachers in Taiwan. The demographic distribution is shown in Table 1:

Table 1. Demographic Distribution of the Subjects

\begin{tabular}{cccc}
\hline \multirow{2}{*}{ Gender } & & Frequency & Percentage(\%) \\
& 1. Male & 206 & 33.8 \\
& 2. Female & 402 & 65.9 \\
\multirow{2}{*}{ School Level } & 1. Elementary school & 311 & 51.0 \\
& 2. Junior high school & 162 & 26.6 \\
& 3. Senior high school & 137 & 22.5 \\
\multirow{2}{*}{ Married Status } & 1. Not married & 175 & 28.7 \\
Service Years & 2. Married & 433 & 71.0 \\
& Range $=1-40$ & $M=15.09$ & $S D=8.19$ \\
\hline
\end{tabular}

Note: $N=610$.

\subsection{Research Tools}

This study adopted three Likert 5-point scales; the scales' validity and reliability are as follows:

\subsubsection{Teachers' Workplace Spirituality Scale}

This study adopted Wu's (2016) [23] "Teachers' Scale for Workplace Spirituality", which was developed for Taiwanese teachers. Those designing this scale referred to the relevant literature and made use of the perspectives of Ashmos and Duchon (2000) [1], as well as of Milliman et al (2003) [5], to prepare the draft of the questionnaires. After undertaking exploratory factor analysis $(\mathrm{EFA})(N=235)$, the scale was divided into 3 factors: A Sense of Meaningful Work (5 items), A Sense of Community (5 items), and A Sense of Organizational Identification (6 items). The total explained variance was $75 \%$, and the total reliability was .95 . 
Furthermore, confirmatory factor analysis (CFA) $(N=378)$ was used to verify the initial 3-factor, 16-item model. According to the results, it was found that the model's preliminary fit was good while its overall fit was acceptable. The composite reliability of the Sense of Meaningful Work was .90 , of the Sense of Community was .85 , and of the Sense of Organizational Identification was 90; all three met the standard of $.60+$. The average extracted variances were $.65, .54$, and .61 , respectively. All three latent variables met the standard of $.50+$.

\subsubsection{Teacher's Sense of Meaning in Life Scale}

The study used Wu's (2014) [24] "Teacher's Sense of Meaning in Life Scale", which incorporated Frankl's $(1967,1988)[25,26]$ three factors in his theory and practice of logotherapy: 1. Freedom of Will, which refers to the individual's attitudes towards suffering (Breitbart, 2001) [27]; 2. Will to Meaning, which concerns our fundamental search for the purpose of life; and 3. Meaning of Life, which has to do with an individual's discovery of the goal and purpose of his/her life. After the drafts of these three scales were examined by the experts, they were directly verified by CFA in order to guarantee that the model's preliminary fit was good. The overall fit of the model was found to be acceptable; the composite reliability of Freedom of Will was found to be .77, of Will to Meaning was found to be .86, and of Meaning of Life was found to be .84, all of which met the standard of $.60+$. The average extracted variances were $.53, .55$ and .51 , respectively, so that the three latent variables all met the standard of $.50+$.

\subsubsection{Teacher's Psychological Well-being Scale}

Our survey of the data regarding Psychological Well-being applied Wu's (2015) [28] Teacher's Psychological Well-being Scale developed for teachers in Taiwan. Its framework is based on six factors proposed by Ryff and Keyes (1995) [29]: Self-acceptance (awareness of one's own limitations), Positive Relations with Others (seeking to develop and maintain warm interpersonal relationships based on mutual trust), Environmental Mastery (shaping one's environment so as to satisfy personal needs and desires), Autonomy (exercising self-determination and maintaining personal authority within a larger social context), having a Purpose in Life (finding meaning in one's efforts and challenges), and Personal Growth (making the most of one's talents and capacities) (Keyes, Shmotkin, \& Ryff, 2002) [10]. After being examined by experts, this scale was verified by the CFA. The model's preliminary fit was found to be good, and its overall fit is to be acceptable. As for composite reliability, Autonomy was found to be .70 , Environmental Mastery to be .78, Self-acceptance to be .84 , Positive Relationships with Others to be .74, Personal Growth to be .81 , and Purpose of Life to be .80 . All of these meet the standard of .60+. The average variances were found to be: Autonomy .44, Environmental Mastery .55, Self-acceptance .64, Positive Relationships with Others .50,
Personal Growth .59, and Purpose of Life .57. Thus, except for Autonomy, all of these latent variables met the standard of $.50+$.

\section{Data Processing and Analysis}

\subsection{Hierarchical Regression Analysis with SPSS 17.0}

This research study employed 3 models in order to put each variable into the equation, for the purpose of understanding its explanatory power. The study used SPSS 17.0 to conduct hierarchical regression analysis, in order to explore the correlations between and among teachers' sense of workplace spirituality, meaning in life, and psychological well-being. The demographic variables were put into an equation as model 1 , workplace spirituality as model 2 , meaning in life as model 3 , and psychological well-being as dependent variable.

\subsection{Control Variables to Dummy}

Among the control variables in this study, gender and married status were nominal variables, and so we employed dummy coding. The male gender was dummied as 0 and the female as 1 . Years of service was taken as an ordinal variable and thrust into the equation directly. In addition, there are three dimensions with workplace spirituality and meaning in life, and the independent variable (total score for psychological well-being) - are ratio variables, so they entered the equation with the row score.

\section{Results}

Regarding Model 1, it is mainly composed of gender, married status, and service years (see Table 2). Model 1's $R^{2}=.03, F=5.72$, and $p=.01$, which gives these demographic variables significant explanatory power in the context of defining "psychological well-being." Among the three demographic variables, only marital status is not statistically significant; the other two, gender $(\beta=-.09$, $t=-2.24, p=.03)$ and service years $(\beta=.10, t=2.22$, $p=.03$ ) are statistically significant, which shows that both variables have significant explanatory power.

As for Model 2, after controlling the three demographic variables' explanatory power, we thrust the dimension of Workplace spirituality into the equation. This model's explanatory power is $R^{2}=.52, F=123.89, p=.00$, showing that Model 2 has substantial explanatory power. As for $\Delta R^{2}=.49, \Delta F=205.97$, and $p=.00$, the data show that after including each dimension of Workplace spirituality, model 2 has incremental statistical meaning; that is, each dimension of Workplace spirituality can increase the model's explanatory power by $49.00 \%$.

Among the three dimensions, Sense of Meaning at Work 
$(\beta=.43, t=11.58, p=.00)$, Sense of Community $(\beta=.19$, $t=4.41, p=.00)$, and Sense of Organizational Identification) $(\beta=.19, t=4.41, p=.00)$ have the explanatory power, and all three $\beta$ values are positive, signifying that a greater sense of having meaningful work, a greater sense of community when at work, and a greater sense of organizational identification all contribute to a greater sense of psychological well-being.

After controlling the explanatory power of Models 1 and 2 , the three dimensions of a meaningful life were thrust into Model 3, and it was found that $R^{2}=.63, F=113.82$, and $p=.00$, showing that Model 3 has explanatory power. As for $\Delta R^{2}=.11, \Delta F=59.78$, and $p=.00$, the increment of model 3 has a statistical significance that can contribute an extra $11.00 \%$ to this model's explanatory power.

Among the three dimensions, Freedom of Will $(\beta=.16$, $t=4.76, p=.00)$, Will to Meaning $(\beta=.15, t=4.02$, $p=.00)$, and Meaning of Life $(\beta=.27, t=8.34, p=.00)$ have the significant explanatory power; and their $\beta$ values are all positive, showing that greater Freedom of Will, Will to Meaning, and Meaning of Life will mean greater psychological well-being.

Table 2. Summary of the hierarchical regression of Workplace spirituality, Meaning in Life, and Psychological Well-being

\begin{tabular}{|c|c|c|c|c|c|c|c|c|c|}
\hline & \multicolumn{9}{|c|}{ Dependent variable (Psychological Well-being) } \\
\hline & \multicolumn{3}{|c|}{$\begin{array}{c}\text { Model } 1 \\
\text { Control variables }\end{array}$} & \multicolumn{3}{|c|}{$\begin{array}{c}\text { Model } 2 \\
\text { Independent variables } \\
\text { (Workplace spirituality) }\end{array}$} & \multicolumn{3}{|c|}{$\begin{array}{c}\text { Model } 3 \\
\text { Independent variables } \\
\text { (Meaning in Life) }\end{array}$} \\
\hline & $\beta$ & $t$ & $p$ & $\beta$ & $t$ & $p$ & $\beta$ & $t$ & $p$ \\
\hline (Constant) & & 35.53 & .00 & & 14.00 & .00 & & 5.14 & .00 \\
\hline Gender & -.09 & -2.24 & .03 & -.06 & -2.22 & .03 & -.08 & -2.97 & .01 \\
\hline Marital status & .05 & 1.19 & .24 & .02 & 0.71 & .48 & .01 & 0.40 & .69 \\
\hline Service years & .10 & 2.22 & .03 & .02 & 0.73 & .47 & .04 & 1.40 & .16 \\
\hline Meaningful Work & & & & .43 & 11.58 & .00 & .15 & 3.68 & .00 \\
\hline Sense of Community & & & & .19 & 4.41 & .00 & .15 & 3.76 & .00 \\
\hline Sense of Organizational Identification & & & & .19 & 4.40 & .00 & .14 & 3.71 & .00 \\
\hline Freedom of Will & & & & & & & .16 & 4.76 & .00 \\
\hline Will to Meaning & & & & & & & .15 & 4.02 & .00 \\
\hline Meaning of Life & & & & & & & .27 & 8.34 & .00 \\
\hline \multicolumn{10}{|l|}{ Model abstract } \\
\hline$R^{2}$ & & .03 & & & .52 & & & .63 & \\
\hline$F$ & & 5.72 & & & 123.89 & & & 113.82 & \\
\hline$p$ & & .01 & & & .00 & & & .00 & \\
\hline$\Delta R^{2}$ & & .02 & & & .49 & & & .11 & \\
\hline$\Delta F$ & & 5.72 & & & 205.97 & & & 59.78 & \\
\hline P of change & & .01 & & & .00 & & & .00 & \\
\hline
\end{tabular}




\section{Discussion}

As for the power of the control variable to explain psychological well-being, when demographic variables like gender, marital status, and years of service are put into Model 1, the results show that such demographic variables have significant explanatory power. And when gender and years of service reach a certain level of significance, these two variables clearly have greater explanatory power than marital status. Moreover, the $\beta$ value of gender is negative, which means male teachers tend to have a greater sense of psychological well-being than do females. This may be due to the fact that male teachers tend to be more outgoing; also, many of them are engaged in administrative affairs, which may tend to give them a greater sense of Autonomy, greater Environmental Mastery, and more Positive Relationships with Others.

With regard to the relationship between having a Workplace spirituality and Psychological Well-being, it was found that Workplace spirituality gains an extra $49.40 \%$ in its explanatory power as a control variable. In fact, all three dimensions of Workplace spirituality have explanatory power and their $\beta$ values are positive, suggesting that the greater one's Sense of having Meaningful Work, one's Sense of Community and one's Sense of Organizational Identification, the greater one's sense of Psychological Well-being will be. Having a Workplace spirituality can also mean enjoying the communal spirit of the workplace, but here it especially means the ability to gain a sense of self-worth from doing a meaningful job, from contributing to the workplace in this way.

On the other hand, according to Maslow's (1969) [31] Hierarchy of Needs Theory, where the highest "human need" is self-actualization, Ashmos and Duchon (2000) [1] have stressed the importance, for a teacher, of connecting with those who have the same goals - which again suggests the importance of the communal spirit of the workplace, of the workplace as community. Of course, meaningful work (a meaningful job) also means that employees can learn a lot, learn many skills from their jobs, and learn to accept challenges and take responsibility for their decisions and actions. (Wrzesniewski, 2001) [14]. De Klerk (2005) [15] believes that their perception that they are doing meaningful work motivates employees to work harder, to perform better, and in this was way they will also gain the approval and respect of their peers, as well as of their boss.

Maslow thought, of course, that the more peak experience employees have, the better able they are to achieve self-actualization. For him this means, as Ryff and Keyes (1995) [29] discuss, the actualizing of one's own potential and thus the reaching of a higher level of psychological well-being. In this context we note that a teacher's job is to nourish and encourage students' positive qualities and characters, to enlighten their minds and thinking, and so theirs is an extremely meaningful and rewarding job. Teachers then should have a clear path toward reaching higher levels of self-actualization, since their job is really to help enable their students to do this.

In this study, then, it was found that our sense of having or living a meaningful life impacts and can explain our sense of psychological well-being. More generally, the greater our Freedom of Will, Will to Meaning, and positive sense of the Meaning of our Life, the greater our psychological well-being will be. This may be especially true for teachers, because when a teacher encounters difficulties in teaching, class management, parent-teacher relationships, and/or administrative jobs in the workplace, he or she already knows that she/he is supported every day by the warmth, positivity, gratitude of her/his students and fellow teachers, the warm communal spirit of her/his workplace.

\section{Suggestions}

Of course, a clear sense that our lives are very meaningful will make us happy, as will good relationships with others, and we not only find meaning and fulfillment in doing our jobs well but also from the long-term friends we make, and talk to every day, in our workplaces. Thus, we concluded from the analyzed data that a very positive and communal workplace spirituality contributes greatly to our sense of meaning in life and to our over-all psychological well-being. Therefore it is clear that teachers should promote in every possible the communal spirit of their workplace; this is closely related to our sense of having a meaningful job, and to the satisfaction we get at our workplace from the sense of community, the sense of being part of an organization. Thus, for the sake of their psychological well-being, teachers should really try to promote and to enhance this communal spirit of/in/at their workplace, which will in turn reinforce their sense of having a happy and meaningful life. Finally, future studies may try to further analyze the factors that influence our sense of psychological well-being, of meaning in life, and of having a very warm and positive communal spirit in/at our workplace, and may also try to further analyze the inter-relationship(s) of/among these factors.

\section{REFERENCES}

[1] D. Ashmos, D. P. Duchon. Spirituality at work: A conceptualization and measure. Journal of Management Inquiry, Vol. 9, No. 2, 134-145, 2000.

[2] S. Krishnakumar, C. P. Neck. The "what", "why" and "how" of spirituality in the workplace. Journal of managerial psychology, Vol. 17, No. 3, 153-164, 2002.

[3] J. Milliman, J. Ferguson, D. Trickett, B. Condemi. Spirit and community at Southwest Airlines. Journal of Organizational Change Management, Vol. 12, No. 3, 221-33, 1999.

[4] J. C. Garcia- Zamor. Workplace spirituality and organizational performance. Public Administration Review, Vol. 63, No. 3, 355-363, 2003. 
[5] J. Milliman, A. J. Czaplewski, J. Ferguson. Workplace spirituality and employee work attitudes: An exploratory empirical assessment. Journal of Organizational Change Management, Vol. 16, No. 4, 426-447, 2003.

[6] M. F. Steger, P. Frazier, S. Oishi, M. Kaler. The meaning in life questionnaire: Assessing the presence of and search for meaning in life. Journal of counseling psychology, Vol. 53, No. 1, 80-93, 2006.

[7] M. E. P. Seligman, M. Csikszentmihalyi. Positive psychology: An introduction. American Psychologist, No. 55, 5-14, 2000.

[8] C. D. Ryff. Happiness is everything, or is it? Explorations of the meaning of psychological well-being. Journal of Personality and Social Psychology, No. 57, 1069-1081, 1989.

[9] R. W. Lent. Toward a unifying theoretical and practical perspective on well-being and psychosocial adjustment. Journal of Counseling Psychology, Vol. 51, 482-509, 2004.

[10] C. L. M. Keyes, D. Shmotkin, C. D. Ryff. Optimizing well-being: The empirical encounter of two traditions. Journal of Personality and Social Psychology, Vol. 82, No. 6, 1007-1022, 2002.

[11] J. M. Salsman, J. S. Lai, H. C. Hendrie, Z. Butt, N. Zill, P. A. Pilkonis, ... D. Cella. Assessing psychological well-being: Self-report instruments for the NIH Toolbox. Quality of Life Research, Vol. 23, No. 1, 205-215, 2014.

[12] C. R. Gale, C. Cooper, I. J. Deary, A. Aihie Sayer. Psychological well-being and incident frailty in men and women: The English Longitudinal Study of Ageing. Psychological medicine, Vol. 44, No. 04, 697-706, 2014.

[13] V. Kinjerski. The Spirit at Work Scale: Developing and Validating a Measure of Individual Spirituality at Work. In J. Neal (Ed.), Handbook of faith and spirituality in the workplace (pp. 383-402). Springer, New York, NY, 2013.

[14] A. W. Wrzesniewski. Crafting a job: Revisioning employees as active crafters of their work. Academy of Management Review, No. 26, 179-202, 2001.

[15] J. J. De Klerk. Spirituality, meaning in life and work wellness: A research agenda. International Journal of Organizational Analysis, No. 13, 64-88, 2005.

[16] K. A. Arnold, N. Turner, J.arling, E. K. Kelloway, M. C. McKee. Transformational leadership and psychological well-being: the mediating role of meaningful work. Journal of occupational health psychology, Vol. 12, No. 3, 193-203, 2007.

[17] D. T. Shek. Meaning in life and psychological well-being: An empirical study using the Chinese version of the Purpose in Life Questionnaire. The Journal of Genetic Psychology, Vol. 153, No. 2, 185-200, 1992.
[18] M. Y. Ho, F. M. Cheung, S. F. Cheung. The role of meaning in life and optimism in promoting well-being. Personality and Individual Differences, No. 48, 658-663, 2010.

[19] S. Vehling, C. Lehmann, K. Oechsle, C. Bokemeyer, A. Krüll, U. Koch, A. Mehnert. Global meaning and meaning-related life attitudes: Exploring their role in predicting depression, anxiety, and demoralization in cancer patients. Supportive Care in Cancer, Vol. 19, No. 4, 513-520, 2011.

[20] A. Aflakseir. Religiosity, personal meaning, and psychological well-being: A study among Muslim students in England. Pakistan Journal of Social and Clinical Psychology, Vol. 9, No. 2, 27-31, 2012.

[21] H. C .Chiu. Quantitative Research Method (II): Statistical Principals and Analysis Techniques, Yehyeh Book, Taipei, Taiwan, 2006.

[22] M. G. Meraviglia. Critical analysis of spirituality and its empirical indicators: prayer and meaning in life. Journal of Holistic Nursing, Vol. 17, No. 1, 18-33, 1999.

[23] H. T. Wu. The Development and Construct Validity of Teachers' Scale of Workplace spirituality. Journal of Health Promotion and Health Education, No. 46, 1-38, 2016.

[24] H. T. Wu. The Development and Construct Validity of Teachers' Sense of Life Meaning Scale. Journal of Educational Theory and Practice, No. 29, 91-122, 2014.

[25] V. E. Frankl. The Doctor and the Soul. New York, 1967.

[26] V. E. Frankl. The Will to Meaning: Foundations and Applications of Logo therapy (2nd ed.), New American Library. New York, 1988.

[27] W. Breitbart. Spirituality and meaning in supportive care: Spirituality-and meaning-centered group psychotherapy interventions in advanced cancer, Spriner-Verlag, New York, 2001.

[28] H. T. Wu. The development and construct validity of Teachers' Psychological Well-being Scale. International Symposium on New Trends and Challenges for Teacher Education, Kaohsiung Normal University, Taiwan, 2015.

[29] C. Ryff, D. C. L. Keyes. The structure of psychological well-being revisited. Journal of Personality and Social Psychology, Vol. 69, No. 4, 719-727, 1995.

[30] C. M. K. Dush. P. R. Amato. Consequences of relationship status and quality for subjective Well-being. Journal of Social and Personal Relationships, Vol. 22, No. 5, 607-627, 2005.

[31] A. H. Maslow. Theory Z. Journal of Transpersonal Psychology, Vol. 1, No. 2, 31-47, 1969. 